\title{
Effects of acetamiprid on Lipaphis pseudobrassicae (Hemiptera: Aphididae) resistant and susceptible to the parasitoid Diaeretiella rapae (Hymenoptera: Braconidae, Aphidiinae) ${ }^{1}$
}

\author{
Jader Braga Maia ${ }^{2,3}$, Paula de Freitas Silva ${ }^{3}$, Marcus Vinicius Sampaio ${ }^{3 *} \mathbb{D}$, Amanda Rosa Custódio de Oliveira ${ }^{3}$, \\ Lohaynne Borges Rosa de Moura ${ }^{3}$, Carolinne Almeida Silva ${ }^{3}$
}

10.1590/0034-737X202067030009

\begin{abstract}
This study evaluated the relationship between the resistance of Lipaphis pseudobrassicae to the parasitoid Diaeretiella rapae and the effects of the insecticide acetamiprid on the aphid. Four groups of L. pseudobrassicae collected in Uberlândia, MG, were used. The first two were formed by individuals of the same clone (C1), which were resistant (C1R) or susceptible (C1S) to the parasitoid. The third group was formed by resistant individuals to the parasitoid descended from a clone collected in canola $(\mathrm{C} 2 \mathrm{R})$ and the fourth group, from a population collected in a commercial plantation of collard greens (P1). Determination of $\mathrm{LD}_{50}$ was done with three replications of 10 aphids, subjected to dose-response assays, with the application of five concentrations of the insecticide acetamiprid $(0.01,0.1$, 1,10 or $100 \mathrm{ng}$ a.i./aphid) and a control treatment consisting of acetone alone. There was no significant difference in the $\mathrm{LD}_{50}$ of individuals of the same clone, $\mathrm{C} 1 \mathrm{R}$ and $\mathrm{C} 1 \mathrm{~S}\left(0.06 \mathrm{ng}\right.$ a.i./aphid for both clones). $\mathrm{C} 2 \mathrm{R}$ had the highest $\mathrm{LD}_{50}(0.14$ ng a.i./aphid), while $\mathrm{P} 1$ had the lowest (0.01 ng a.i./aphid). These results suggest that resistance against the parasitoid is not, therefore, associated with the effects of insecticide on L. pseudobrassicae.
\end{abstract}

Keywords: aphids; biological control; chemical control; insecticide resistance.

\section{INTRODUCTION}

The aphid Lipaphis pseudobrassicae (Davis) (Hemiptera: Aphididae) is a cosmopolitan pest of Brassica, directly damaging crops by feeding on the leaves, causing deformation and yellowing, and indirectly damaging plants by transmitting more than ten types of plant pathogenic viruses, among them, collard green black ring and the mosaics of cauliflower, turnip and radish (Peña-Martinez, 1992; Blackman \& Eastop, 2007). Because it is widely distributed, control of this aphid is extremely important throughout Brassica producing regions in such crops as canola, collard greens, broccoli, and cauliflower (Blackman \& Eastop, 2000).

Biological control plays an important role in Integrated Pest Management (IPM) programs, especially considering its low cost and general lack of synthetic chemicals (Parra $\&$ Coelho, 2019). The main natural enemy of aphids in Brassica crops is the parasitoid Diaeretiella rapae (McIntosh) (Hymenoptera: Braconidae, Aphidiinae) (Starý et al., 2007; Akhtar et al., 2010; Sampaio et al., 2017); however, the low parasitism rate of $D$. rapae in $L$. pseudobrassicae, both in the field and laboratory, suggests that the population of L. pseudobrassicae in Uberlândia-MG is formed mostly of clones resistant to this parasitoid (Oliveira et al., 2013; Sampaio et al., 2017; Ferreira et al., 2018).

The cause of such resistance in L. pseudobrassicae is still under investigation; however, association with secondary symbionts is a possibility, since aphids susceptible to the parasitoid have been obtained within

\footnotetext{
Submitted on February 19th, 2020 and accepted on April 14th, 2020

${ }^{1}$ This study is part of the Master's dissertation of the second author.

2 Universidade Federal do Triângulo Mineiro, Campus Universitário de Iturama, Minas Gerais, Brazil. jader.maia@uftm.edu.br;

${ }^{3}$ Universidade Federal de Uberlândia, Instituto de Ciências Agrárias, Uberlândia, Minas Gerais, Brazil. paula_freitas_6@yahoo.com.br; mvsampaio@ufu.br; oliveira.arc@gmail.com; lohaynne-borges@hotmail.com; carolinneagro@gmail.com

*Correspondence author: mvsampaio@ufu.br
} 
the offspring of resistant aphids (Ferreira et al., 2018). The association of aphids with these symbionts can result in adaptive advantages, such as increased heat tolerance, the ability to use host plants that, without the symbionts, would not be suitable for aphid feeding, and resistance to parasitoids (Chen et al., 2000; Oliver et al., 2003; Tsuchida et al., 2002; Vorburger et al., 2013; Cayetano et al., 2014).

Chemical control is commonly used to control agricultural pests, but frequent spraying and the improper use of these products (failure to observe the recommended dose, spraying interval, or rotation of active ingredients) has led to the increased pesticide resistance in populations of many pest insects against a number of insecticides (Chen \& Stelinski, 2017). The dose required to eliminate $50 \%$ of the population $\left(\mathrm{LD}_{50}\right)$ of resistant insects is greater than that required for control of susceptible populations, and $\mathrm{LD}_{50}$ values are used to monitor the level of resistance in a population or pest (Szendrei et al., 2011; Paramasivam \& Selvi, 2017). Moreover, it is not only the lethal effect of an insecticide that determines its effect on an insect's population, but also any sub-lethal effects it may cause, such as decreased fertility and longevity and changes in the development period (Stark \& Rangus, 1994; Storch et al., 2007; Miao et al., 2016).

Resistance to insecticides can be due to behavior modification of the insect, changes in cuticle composition reducing penetration, metabolic resistance, or modifications in insecticide target sites (Mbogo et al., 1996; Hemingway, 2000; Mathenge et al., 2001; FrenchConstant et al., 2004; Dang et al., 2017; Balabanidou et al., 2018). Recently, the fact that secondary symbionts can change enzyme production was recognized (Guidolin et al., 2018), a finding that may be used to create greater susceptibility to insecticides in aphids that present such associations with secondary symbionts (Skaljac et al., 2018).

Studies have demonstrated that biological control of the aphid L. pseudobrassicae with the parasitoid D. rapae is currently not effective due to the aphid's resistance to the parasitoid (Oliveira et al., 2013; Sampaio et al., 2017; Ferreira et al., 2018). A number of chemical control options have been considered, particularly using neonicotinoids such as acetamiprid, since acetamiprid is a systemic insecticide, absorbed by the plant and translocated throughout the plant in the sap in lethal amounts to sapfeeding insects such as the aphids (Tomizawa \& Casida, 2003; Faria, 2009). However, it is not known if the resistance of $L$. pseudobrassicae to $D$. rapae changes the effects of the insecticide on aphids. Therefore, this study determined the $\mathrm{LD}_{50}$ of the insecticide acetamiprid and its sub-lethal effect on fertility of resistant or susceptible clones of L. pseudobrassicae to see if there is such a relationship between resistance of the aphid to the parasitoid and the lethal and sub-lethal effects of the insecticide on L. pseudobrassicae.

\section{MATERIAL AND METHODS}

\section{Plant production and insect collection and rearing}

Collard greens (Brassica oleracea var. acephala L.), cultivar Manteiga da Georgia, seedlings were produced in the greenhouse for this study, using commercial seeds from TopSeed ${ }^{\circledR}$. When seedlings had one pair of true leaves, seedlings were transplanted to plastic pots $(15 \mathrm{~cm}$ height and $13 \mathrm{~cm}$ diameter) containing the organic substrate Bioplant ${ }^{\circledR}$. Plants were used for aphid rearing, and also for experiments when they had six true leaves.

Colonies of M. persicae and L. pseudobrassicae were maintained in the laboratory. Aphids were reared on 90$\mathrm{mm}$ dia disks of collard green leaves, placed in 100-mm dia Petri plates containing water-agar at $1 \%$. The plates were maintained in a acclimatized chamber $\left(23 \pm 2^{\circ} \mathrm{C}, 70 \pm 10 \mathrm{RH} \%\right.$ and a 12:12 h L:D photoperiod), and the leaf disks were changed every four days.

Colonies of four groups of L. pseudobrassicae collected in Uberlândia were maintained for use in the experiments. The first two groups (C1R and C1S) were created by laboratory rearing and were comprised of individuals of the same clone collected in collard greens plants in the greenhouse (at $18^{\circ} 53^{\prime} 04.7^{\prime \prime} \mathrm{S}$ and $48^{\circ} 15^{\prime} 36.6^{\prime \prime}$ W) at Campus Umuarama of Federal University of Uberlândia (UFU) and then either selected as resistant (C1R) to the parasitoid D. rapae or susceptible (C1S). A third group was formed using resistant individuals of another clone (C2R) collected in canola plants at the Água Limpa farm, of UFU. The fourth group (resistance to $D$. rapae unknown) was composed of individuals from a population (P1) collected in a commercial collard green field (19' 1 '54" S and 48 11'26" W).

Parasitoids (D. rapae) were reared from M. persicae, $B$. brassicae, and L. pseudobrassicae colonies that contained parasitized aphids (mummies), collected from commercial area of collard greens production in UberlândiaMG in field and in the greenhouse at Campus Umuarama of UFU. Each mummy was placed in a 2-mL Eppendorf tube and held in the laboratory (at $23 \pm 2{ }^{\circ} \mathrm{C}, \mathrm{RH}=70 \pm 10 \%$ and a 12:12 $\mathrm{h}$ LD photoperiod) until adult parasitoids emergence. Subsequently, adults were fed with droplets of honey diluted in water (honey 50\%). The parasitoids were maintained in pairs in the same type of tubes and, after mating, females were used to produce more parasitoids. Parasitoid rearing was done using $2^{\text {nd }}$ instar nymphs of $M$. persicae as hosts. First instar nymphs were obtained from adults that were placed in Petri plates 
containing leaf disks of collard greens for 24 hours, after which the adult aphids were removed and the first instar nymphs left in the dish. Twenty-four hours later, these nymphs were in the $2^{\text {nd }}$ instar. One mated female of $D$. rapae with no previous oviposition experience was released in each Petri plate, each containing forty $2^{\text {nd }}$ instar nymphs of $M$. persicae and left for two hours for oviposition. Subsequently, the female parasitoid was removed and the aphid nymphs were held in an acclimatized chamber $\left(22^{\circ} \mathrm{C}\right.$ and a 12:12 $\mathrm{h} \mathrm{L}: \mathrm{D}$ photoperiod $)$ until mummies were formed, about 10 to 15 days later and the parasitoids were used to select resistant clones.

\section{Selection of clone C1R and C1S of $L$. pseudobrassicae collected in collard green}

Colonies of L. pseudobrassicae were collected in collard greens plants in the greenhouse (at 18 $53^{\prime} 04.7^{\prime \prime} \mathrm{S}$ and $48^{\circ} 15^{\prime} 36.6^{\prime \prime} \mathrm{W}$ ). Leaves containing aphids were taken to the laboratory and eight individual aphids were placed in individual Petri plates containing collard green leaf disks overlaying the water-agar (1\%) to form one colony of each clone (C1, Cx1, Cx2, Cx3, Cx4, Cx5, Cx6, Cx7). Aphids reproduce by thelytokous parthenogenesis, and thus each colony arising from a single individual is formed by genetically identical individuals (Blackman \& Eastop, 2000). After population growth of the colonies, adults of each clone were maintained in distinct Petri plates, containing the collard green disks over water-agar (1\%), and removed after 24 hours, to form a group of only $1^{\text {st }}$ instar nymphs. These L. pseudobrassicae nymphs reached the $4^{\text {th }}$ instar in 72 hours and were used to assess the level of resistant to $D$. rapae in each of the eight clones started from aphids collected from collard greens (see method details below).

Approximately twelve adult aphids of each of the eight clones were placed in separate Petri dishes with a collard green leaf disk. Adults were removed 24 hours later, and the $1^{\text {st }}$ instar nymphs held for a further 72 hours until they reached the $4^{\text {th }}$ instar. Twenty-two to $354^{\text {th }}$ instar nymphs of each clone were then held individually in Petri dishes and subjected to a single oviposition by $D$. rapae. Oviposition was observed under the stereoscopic microscope, and each aphid nymph received one oviposition in the abdomen; if parasitism occurred on the legs, head or siphunculus, the nymphs were discarded. Parasitized aphids were then maintained in individual Petri plates in an acclimatized chamber. Among the clones evaluated, two had only individuals susceptible to the parasitoid and were discarded and six were selected as resistant (all aphids reached adulthood and did not mummify). The clone $\mathrm{C} 1$ was read in the laboratory specifically to select both resistant and susceptible individuals from the same clone.
To obtain susceptible individuals within a resistant clone, fourth instar nymphs of the clone $\mathrm{C} 1$ were subjected to a single oviposition of $D$. rapae (as previously described above). Each female parasitoid was allowed to parasitize a maximum of ten nymphs until 65 aphids were parasitized. Nevertheless, it is important to mention that the mummification proves the susceptibility of the aphid, but the survival does not necessarily prove resistance, thus the parasitism of a great number of individuals is necessarily to prove the resistance of the clone. Daily observations were made for 10 days, evaluating the number of aphids reaching adulthood and remaining alive (resistant) and those that were soon after molting to adults transformed into mummies (susceptible) (Ferreira et al., 2018). Fourth instar nymphs were used because even susceptible aphids that are successfully parasitized by $D$. rapae at this developmental stage can reach adulthood and reproduce before dying and becoming mummies (Ferreira et al. 2018).

For clone $\mathrm{C} 1$, only one specimen was transformed into mummy and the other 64 were considered to be resistant. Thus, the clone $\mathrm{C} 1$ was reared as two groups, one of individuals resistant to $D$. rapae $(\mathrm{C} 1 \mathrm{R})$ and the other of susceptible individuals (C1S). Twenty $2^{\text {nd }}$ instar nymphs of $\mathrm{C} 1 \mathrm{~S}$ and twenty of $\mathrm{C} 1 \mathrm{R}$ were subjected to a single oviposition of $D$. rapae to confirm their susceptibility or resistance. Daily observations were made for 15 days and the number of aphids that reached adulthood and reproduced (resistant) and those that were mummified (susceptible) was recorded. None of the twenty C1R nymphs parasitized by $D$. rapae mummified, confirming that $100 \%$ of the individuals were resistant. In contrast, 19 out of the $20 \mathrm{C} 1 \mathrm{~S}$ parasitized nymphs were mummified, confirming the susceptibility of C1S.

\section{Selection of clone C2R of L. pseudobrassicae collected in canola}

Colonies of $L$. pseudobrassicae were collected in canola plants in the Capim Branco farm of UFU (18 ${ }^{\circ} 52^{\prime}$ 50.63" S and $48^{\circ} 20^{\prime} 32,07^{\prime \prime} \mathrm{W}$ ). Leaves containing aphids were taken to the laboratory and two individual aphids (clones $\mathrm{C} 2$ and C3) were placed in individual Petri plates containing collard green leaf disks overlaying the water-agar (1\%) to form one colony of each clone. After population growth of the colonies, $4^{\text {th }}$ instar nymphs of L. pseudobrassicae were used to assess the level of resistant to D. rapae (as described above) in each of the two clones started from aphids collected from canola fields.

To assess the level of resistance to parasitism of the two canola field-origin aphid colonies, ten $4^{\text {th }}$ instar nymphs from each a L. pseudobrassicae clone (C2, C3) were placed in batches (of 10 aphids) in Petri plates containing a collard leaf disk, where one $D$. rapae mated 
female, no older than 48 hours and with no previous oviposition experience was released. Oviposition was observed under the stereoscopic microscope (as previously described above). Parasitized aphids were removed from the plate immediately after been parasitized and then maintained in individual Petri plates in an acclimatized chamber. Each parasitoid female was allowed to parasitize from six to 10 aphids of the aphids in a given dish (10 aphids), until 23 aphids were parasitized per clone (using three parasitoid females per clone). Daily observations were made for 15 days to evaluate the number of aphids that did not mummify (resistant) and the number of those that became mummies (susceptible).

For clone $\mathrm{C} 2$, none of the 23 parasitized aphids transformed into a mummy, and therefore we considered clone $\mathrm{C} 2$ to be resistant to the parasitoid. Similarly, for clone $\mathrm{C} 3$, only one specimen was transformed into mummy and the other 22 were considered to be resistant. Thus, clone $\mathrm{C} 2$ was also chosen for the experiment as a resistant clone.

Twenty $2^{\text {nd }}$ instar nymphs of $\mathrm{C} 2$ clone were subjected to a single oviposition of $D$. rapae to confirm their resistance. Daily observations were made for 15 days to confirm the formation of mummies. Since all 20 aphids reached adulthood and did not mummify, resistance of clone $\mathrm{C} 2$ to $D$. rapae was confirmed and it was designated as $\mathrm{C} 2 \mathrm{R}$.

\section{Experimental protocol}

The lethal and sub-lethal effects of acetamiprid on $L$. pseudobrassicae clones that were either resistant or susceptible to the parasitoid $D$. rapae were evaluated with dose-response assays, using $\mathrm{LD}_{50}$ values as the measure of mortality and the sub-lethal effects of acetamiprid on aphid fecundity. The doses to be applied per aphid were determined in preliminary tests. Insecticide solutions were prepared from the technical product, using acetone as the solvent. Five concentrations $(0.01,0.1,1,10$ or $100 \mathrm{ng}$ a.i./ aphid) of acetamiprid and a control treatment with just acetone were used. A micro syringe coupled to an automatic dispenser was used to apply a volume of 0.20 $\mu \mathrm{L}$ on each aphid. This volume was based on the average body mass of an adult aphid $(0.4809 \mathrm{mg})$, obtained from the evaluation of the mass of 350 adult aphids, weighed in 10 groups of 35 specimens, using an analytical scale.

Three replications were done for each insecticide dose and aphid group, each replicate being set up in a 100-mm dia Petri plate containing one collard green disk over wateragar (1\%). In each dish (replicate) we placed ten 24-hour old L. pseudobrassicae adults. The plates were incubated in an acclimatized chamber at $25 \pm 2^{\circ} \mathrm{C}, \mathrm{RH} 70 \%$ and a $12: 12$ h L:D photoperiod immediately after the appropriate insecticide dose had been applied to each aphid. Evaluations of aphid survival were done at 24, 48 and 72 hours after the application, determining the number of dead specimens as well as the number of aphid nymphs produced by each chemically treated mother aphid.

\section{Data analysis}

The experimental design was completely randomized, with three replications, and the analyses were done with the software R (2016). Data were submitted to Shapiro and Fligner tests to confirm the assumptions of normality of error distribution and homogeneity of variances, respectively. Mortality data were analyzed using the package DRC (Ritz \& Streibig, 2005) using the Chi-square test. We determined the values of acute toxicity $\left(\mathrm{LD}_{50}\right)$ and the $95 \%$ CI of aphid mortality at 48 hours after insecticide application. $\mathrm{LD}_{50}$ values were expressed in nanograms of active ingredient per aphid (ng a.i./aphid) and in nanograms of active ingredient per milligram of aphid (ng a.i. $\mathrm{mg}^{-1}$ aphid). The data on L. pseudobrassicae fertility (number of nymphs produced after 72 hours) were analyzed using the General Linear Model and adjusted to the Poisson distribution, with a "log" link function, in which the aphid groups, dilutions and its interaction were considered as fixed factors.

\section{RESULTS}

The greatest mortality from acetamiprid occurred in clone $\mathrm{C} 1 \mathrm{~S}$ and population $\mathrm{P} 1$ at 0.01 and $0.1 \mathrm{ng}$ a.i./aphid, with values of $53.3 \%$ and $53.3 \%$, and $76.6 \%$ and $66.6 \%$ dead aphids (out of 30 aphids per treatment), respectively. Mortality of $93,3 \%, 86,6 \%$, and $90 \%$ of the specimens in the clones $\mathrm{C} 1 \mathrm{R}, \mathrm{C} 1 \mathrm{~S}$ and population $\mathrm{P} 1$, respectively, was observed at the concentration $1 \mathrm{ng}$ a.i./aphid of acetamiprid after 72 hours of exposition. Mortality of the clone $\mathrm{C} 2 \mathrm{R}$ was lower than that of the other groups at the concentrations of $0.01,0.1$ and $1 \mathrm{ng}$ a.i./aphid. The insecticide acetamiprid caused $100 \%$ mortality at the two greatest concentrations, 10 and $100 \mathrm{ng}$ a.i./aphid, while the control treatment caused no mortality (Table 1).

The clone $\mathrm{C} 2 \mathrm{R}$ had the highest $\mathrm{LD}_{50}$ value. The population $\mathrm{P} 1$ had the smallest $\mathrm{LD}_{50}$ value and, therefore, was considered the most susceptible to the insecticide acetamiprid. The $\mathrm{LD}_{50}$ values of the $\mathrm{C} 1 \mathrm{R}$ (resistant) and C1S (susceptible) clones were not statistically different (Table 2), indicating that resistance to the parasitoid did not change the effect of the insecticide acetamiprid on $L$. pseudobrassicae. Moreover, the $\mathrm{LD}_{50}$ values of the two resistant clones (C1R and C2R) were different (Table 2). The clone $\mathrm{C} 2 \mathrm{R}$ had a greater $\mathrm{LD}_{50}$ than that of clone $\mathrm{C} 1 \mathrm{R}$, indicating that the mortality due the insecticide acetamiprid is related to the clone, not to resistance to the parasitoid (Table 2).

Fertility of aphids was affected by pesticide applications but not by their degree of resistance to the 
parasitoid. Significant differences were observed for the number of nymphs produced by each clone 72 hours after applying the insecticide acetamiprid $\left(\mathrm{W}=1.057 \mathrm{e}^{-07}\right)$. Low pesticide doses (0.01 and $0.1 \mathrm{ng}$ a.i./aphid) did not affect nymphal production for any of the aphid treatment groups, including the control (Figure 1). Reduction in nymphal production started at $1 \mathrm{ng}$ a.i./aphid for all aphid groups. At 10 ng a.i./aphid, C1R, C1S and P1 ceased reproduction and no aphid group reproduced at the greatest dose evaluated, $100 \mathrm{ng}$ a.i./aphid. The clone C2R had the greatest fertility, in the control as well as at the doses 0.01 , 0.1, 1 and $10 \mathrm{ng}$ a.i./aphid (Figure 1). The production of nymphs in clones $\mathrm{C} 1 \mathrm{R}$ and $\mathrm{C} 1 \mathrm{~S}$ and the population $\mathrm{P} 1 \mathrm{did}$ not differ among themselves or with the control at $0.01,1$ and $10 \mathrm{ng}$ a.i./aphid (Figure 1). In contrast, at $0.1 \mathrm{ng}$ a.i./ aphid, $\mathrm{C} 1 \mathrm{~S}$ produced more nymphs than $\mathrm{C} 1 \mathrm{R}$ and $\mathrm{P} 1$. The greatest reproduction of clone $\mathrm{C} 2 \mathrm{R}$ for all the doses of acetamiprid for which reproduction was observed,

Table 1: Percentage of mortality of four groups of Lipaphis pseudobrassicae (30 aphids of each group per dose) resistant and susceptible to the parasitoid Diaeretiella rapae, after topical application of five doses of the insecticide acetamiprid in nanograms of active ingredient per aphid (ng a.i./aphid) and in the control (acetone)

\begin{tabular}{|c|c|c|c|c|c|}
\hline \multirow{3}{*}{$\begin{array}{l}\text { Concentration } \\
\text { (ng a.i./aphid) }\end{array}$} & \multirow{3}{*}{$\begin{array}{c}\text { Clones } \\
\text { and population }\end{array}$} & \multicolumn{4}{|c|}{ Mortality (\%) } \\
\hline & & \multicolumn{3}{|c|}{ Exposition (hours) $^{1}$} & \multirow{2}{*}{ Total } \\
\hline & & 24 & 48 & 72 & \\
\hline \multirow{4}{*}{0.01} & C1R & 0.0 & 10.0 & 16.6 & 26.6 \\
\hline & $\mathrm{C} 1 \mathrm{~S}$ & 3.3 & 13.3 & 36.6 & 53.3 \\
\hline & $\mathrm{C} 2 \mathrm{R}$ & 0.0 & 3.3 & 13.0 & 16.6 \\
\hline & P1 & 40.0 & 3.3 & 10.0 & 53.3 \\
\hline \multirow{4}{*}{0.1} & C1R & 10.0 & 10.0 & 6.6 & 26.6 \\
\hline & $\mathrm{C} 1 \mathrm{~S}$ & 10.0 & 23.3 & 43.3 & 76.6 \\
\hline & $\mathrm{C} 2 \mathrm{R}$ & 3.3 & 6.6 & 3.3 & 13.3 \\
\hline & $\mathrm{P} 1$ & 60.0 & 3.3 & 3.3 & 66.6 \\
\hline \multirow{4}{*}{1} & $\mathrm{C} 1 \mathrm{R}$ & 20.0 & 46.6 & 26.6 & 93.3 \\
\hline & $\mathrm{C} 1 \mathrm{~S}$ & 20.0 & 50.0 & 16.6 & 86.6 \\
\hline & $\mathrm{C} 2 \mathrm{R}$ & 16.6 & 26.6 & 10.0 & 53.3 \\
\hline & $\mathrm{P} 1$ & 70.0 & 16.6 & 3.3 & 90.0 \\
\hline \multirow{4}{*}{10} & $\mathrm{C} 1 \mathrm{R}$ & 90.0 & 10.0 & - & 100.0 \\
\hline & $\mathrm{C} 1 \mathrm{~S}$ & 66.6 & 26.6 & 6.6 & 100.0 \\
\hline & $\mathrm{C} 2 \mathrm{R}$ & 76.6 & 23.3 & 0.0 & 100.0 \\
\hline & $\mathrm{P} 1$ & 100.0 & - & - & 100.0 \\
\hline \multirow{4}{*}{100} & $\mathrm{C} 1 \mathrm{R}$ & 100.0 & - & - & 100.0 \\
\hline & $\mathrm{C} 1 \mathrm{~S}$ & 100.0 & - & - & 100.0 \\
\hline & $\mathrm{C} 2 \mathrm{R}$ & 63.3 & 36.6 & - & 100.0 \\
\hline & $\mathrm{P} 1$ & 100.0 & - & - & 100.0 \\
\hline \multirow{4}{*}{ Control } & C1R & 0.0 & 0.0 & 0.0 & 0.0 \\
\hline & $\mathrm{C} 1 \mathrm{~S}$ & 0.0 & 0.0 & 0.0 & 0.0 \\
\hline & $\mathrm{C} 2 \mathrm{R}$ & 0.0 & 0.0 & 0.0 & 0.0 \\
\hline & $\mathrm{P} 1$ & 0.0 & 0.0 & 0.0 & 0.0 \\
\hline
\end{tabular}

'Hours after exposition to the product; C1R: Clone one, resistant; C1S: Clone one, susceptible; C2R: Clone two, resistant; P1: Population collected in a commercial area of collard greens. *average body weight of one aphid: $0.4809 \mathrm{mg}(\mathrm{n}=350)$.

Table 2: Acute toxicity $\left(\mathrm{LD}_{50}-48\right.$ hours) of acetamiprid in four groups of Lipaphis pseudobrassicae resistant and susceptible to the parasitoid Diaeretiella rapae

\begin{tabular}{lcccccc}
\hline Clone & $\mathbf{L D}_{\mathbf{5 0}}{ }^{\mathbf{a}}$ & $\mathbf{C I 9 5 \%}^{\mathbf{b}}$ & $\mathbf{L D}_{\mathbf{5 0}} \mathbf{c}^{*}$ & $\mathbf{C I 9 5 \%}^{\mathbf{d}}$ & $\boldsymbol{\chi}^{\mathbf{2}} \mathbf{e}^{\mathbf{*}}$ & $\boldsymbol{D f}^{\mathbf{f}}$ \\
\hline C1R & 0.06 & $0.01-0.10$ & 0.12 & $0.02-0.21$ & 12.924 & 10 \\
C1S & 0.06 & $0.03-0.10$ & 0.12 & $0.06-0.21$ & 15.194 & 13 \\
C2R & 0.14 & $0.07-0.20$ & 0.29 & $0.14-0.41$ & 12.294 & 10 \\
P1 & 0.01 & $0.00-0.02$ & 0.02 & $0.00-0.04$ & 8.2731 & 10 \\
\hline
\end{tabular}

${ }^{\mathrm{a}} \mathrm{LD}_{50}$ in nanograms of active ingredient per aphid (ng a.i./aphid); ${ }^{\mathrm{b}}$ Confidence interval of $95 \%$ in ng a.i./ aphid; ${ }^{\mathrm{c}} \mathrm{LD}_{50}$ in nanograms of active ingredient per milligram of aphid (ng i.a. mg ${ }^{-1}$ aphid); ${ }^{\mathrm{d}}$ Confidence interval of $95 \%$ in ng i.a. $\mathrm{mg}^{-1}$ of aphid; ${ }^{\mathrm{e}}$ Chi-square of the model; 'Degrees of freedom; *average body mass of an aphid: $0.4809 \mathrm{mg}(\mathrm{n}=350)$; C1R: Clone one, resistant; C1S: Clone one, susceptible; C2R: Clone two, resistant; P1: Population collect in a commercial area of collard greens. 
indicates that this is a characteristic of the clone and is not related to resistance to the parasitoid or to a smaller sublethal effect of the insecticide on this clone (Figure 1). In general, a reduction in production of nymphs was most related to increased aphid death, especially 24 and 48 hours after exposure to acetamiprid (Table 1, Figure 1).

\section{DISCUSSSION}

Few studies have been done determining the $\mathrm{LD}_{50}$ of insecticides to aphids, and those that have were done mostly with plant extracts and essential oils. There are more studies determining $\mathrm{LC}_{50}$ (median lethal concentration) values, probably due to the greater difficulty of the topical application on aphids for the determination of $\mathrm{LD}_{50}$, especially due to their small size (Konno \& Omoto, 2006; Silva et al., 2009; Breda et al., 2011; Tran et al., 2016).

Comparing the $\mathrm{LD}_{50}$ of L. pseudobrassicae with that of other insects with greater body mass makes it clear that the reduced size of the aphid results in a low acetamiprid $\mathrm{LD}_{50}$, varying from 0.01 to $0.14 \mathrm{ng}$ a.i./aphid. For instance, studies done with a topical application of imidacloprid, another neonicotinoid, on Apis melifera (L.) bees, presented $\mathrm{LD}_{50}$ of 49 to $102 \mathrm{ng} /$ bee (Nauen et al., 2001; Schmuck et al., 2003). The toxic effect of neonicotinoids on aphids is known to be greater than that of insecticides of other chemical groups, Gaber et al. (2015) demonstrated the great efficacy of the commercial product Mospilan, manufactured with acetamiprid, in the control of the aphid A. gossypii on cotton. Those authors observed a reduction of $85 \%$ of the aphid population 21 days after the treatment. According to Konno \& Omoto (2006), for Aphis gossypii Glover, the lethal concentration of imidacloprid was half that of carbosulfan (a carbamates) and only about $2 \%$ of endosulfan (a cyclodiene chlorates). Similarly, Skaljac et al. (2018) found values for the lethal concentration of imidacloprid for Acyrthosiphum pisum (Harris) to be only about $4 \%$ of cyantraniliprole, $0.1 \%$ of spirotetramat, $0.03 \%$ of methomyl and $0.006 \%$ of chlorpyriphos-methyl.

We found no relation between resistance of $L$. pseudobrassicae to the parasitoid $D$. rapae and the effects of the insecticide acetamiprid, be it through its lethal effect, evaluating the $\mathrm{LD}_{50}$, or as sub-lethal effects, through the evaluation of L. pseudobrassicae fertility. Aphids resistant to the parasitoid have a clear adaptive advantage in the presence of the parasitoids (Oliveira et al., 2013); however, in the absence of the parasitoid there can be adaptive advantages (Cayetano et al., 2014) or costs (Vorburger et al., 2013; Skaljac et al., 2018) to being resistant to the parasitoid. For instance, Aphis fabae Theobald infected by Hamiltonella defensa, was resistant to the parasitoid Lysiphlebus fabarum (Marshall) and its life expectation and reproduction were greater than that of individuals that were not resistant to the parasitoid (Cayetano et al., 2014). In contrast, Skaljac et al. (2018), found a reduction in reproduction and size of aphids that were resistant to the parasitoid Aphidius ervi (Haliday) through symbiosis with Serratia symbiotica, although clones of A.pisum that were resistant to the parasitoid were more susceptible to the insecticides imidacloprid, chlorpyriphos-methyl, methomyl, cyantraniliprole, and spirotetramat, in contrast to the present study where no adaptive advantage or disadvantage was observed in the aphids resistant to $D$. rapae in relation to the effects of the insecticide.

The evaluation of nymphal production in our control, with no insecticide application, demonstrated that the clone $\mathrm{C} 2 \mathrm{R}$, resistant to the parasitoid, had the greatest fertility. However, this is a clone effect, not an effect from the resistance to the parasitoid, since resistant $(\mathrm{C} 1 \mathrm{R})$ and

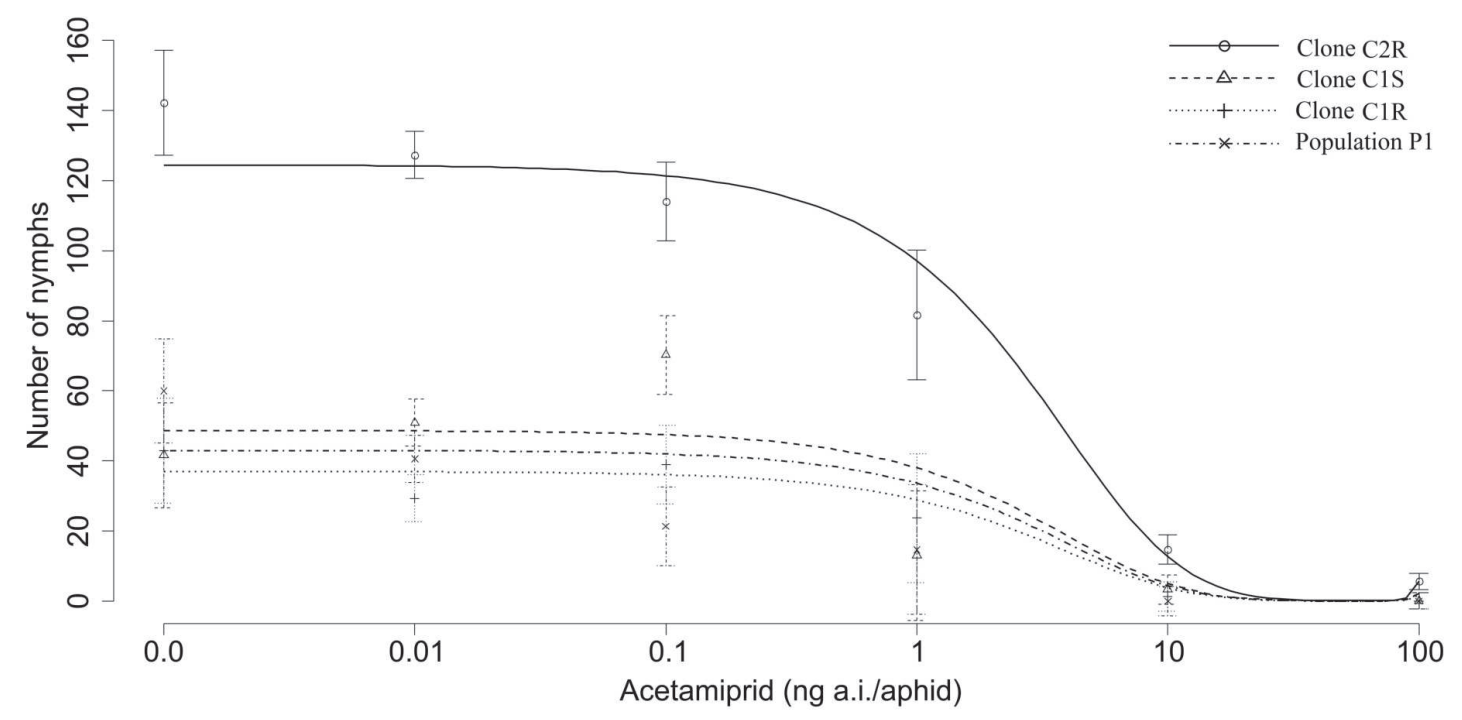

Figure1: Number of nymphs produced by four groups of Lipaphis pseudobrassicae for 72 hours after the application of five doses of the insecticide acetamiprid, in nanograms of active ingredient per aphid (ng a.i./aphid) and in the control (acetone). 
susceptible (C1S) specimens of the same clone had the same fertility. Similarly, the fertility of susceptible clone C1S was similar to that of population $\mathrm{P} 1$.

Another adaptive aspect to be considered is the negative effect of resistance to insecticide, since there tend to be adaptive costs linked to such resistance. In this study, the clone $\mathrm{C} 2 \mathrm{R}$, resistant to the parasitoid, also had greater $\operatorname{LD}_{50}(0.29 \mu \mathrm{g}$ a.i./mg aphid $)$ and also greater nymphal production than the other clones, with no adaptive cost, at least in terms of fertility. The superior reproduction of clone $\mathrm{C} 2 \mathrm{R}$ compared other treatments was observed both in the absence (control) and in the presence of selection pressure (insecticide treatments), indicating that this is an advantageous characteristic of the clone, which, by having the smallest mortality, had the greatest population increase, even when exposed to acetamiprid. According to Belinato \& Martins (2016), in the absence of insecticides, susceptible individuals can have reproductive advantages, and therefore levels of resistance in the population tend to decrease. Studies related to the adaptive cost associated to resistance have found contrasting results. Hollingsworth et al. (1997) observed that a line of A. gossypii resistant to the insecticide methomyl, had greater fertility than a susceptible line. Similarly, Eggers-Schumacher (1983) reported that a resistant line of $M$. persicae had a reproductive advantage in relation to the susceptible line in the absence of selection pressure. In contrast, Konno \& Omoto (2006) observed that the line of A. gossypii resistant to the insecticide carbosulfan was at a reproductive disadvantage in relation to the susceptible line in the absence of selection pressure, similar to Stone et al. (2000), who reported that lines of Schizaphis graminum (Rondani) resistant to five organophosphate insecticides had a reproductive disadvantage compared to susceptible ones.

Adaptive costs of resistance can be related to other characteristics besides those associated with aphid reproduction, such as mobility or response to alarm pheromones. Foster et al. (2010) observed that M. persicae resistant to insecticides had lower mobility, reducing its ability to flee from attack by $D$. rapae compared to susceptible aphids, leading to higher parasitism. The present study, however, did not consider behavioral aspects in the evaluation of the consequences of resistance to acetamiprid.

The parasitoid D. rapae is the most important natural enemy for aphid control in Brassica crops (Sampaio et al., 2017). However, a high proportion of resistant individuals in the population of L. pseudobrassicae in Uberlândia makes biological control from this parasitoid a less effective tool (Oliveira et al., 2013; Sampaio et al., 2017; Ferreira et al., 2018).

\section{CONCLUSION}

The use of the parasitoid $D$. rapae for the control of the aphid L. pseudobrassicae in Brassica crops in Uberlândia-MG is ineffective since most individuals are resistant to the parasitoid. Thus, the confirmation that there is no relation between resistance to the parasitoid and the effects of the insecticide acetamiprid makes the use of chemical control with neonicotinoids a possible option for the control of L. pseudobrassicae in Brassica.

\section{ACKNOWLEDGEMENTS, FINANCIAL SUPPORT AND FULL DISCLOSURE}

The authors acknowledge the financial support of Fundação de Amparo a Pesquisa do Estado de Minas Gerais (FAPEMIG) for the PROJECT N ${ }^{\circ}$ BPD-00624-14 and for the graduate and undergraduate scholarships. Also the National Council of Scientific and Technological Development (CNPq) and São Paulo Research Foundation (FAPESP) are acknowledged for providing financial support to the INCT-HYMPAR and the Coordination of Improvement of Higher Education Personnel (CAPES) for the graduate scholarships.

The authors are unaware of any conflicts of interest in carrying the research and publishing the manuscript.

\section{REFERENCES}

Akhtar MS, Dey D, Usmani MK \& Choudhury RA (2010) Seasonal abundance of Diaeretiella rapae (McIntosh) (Braconidae: Aphidiinae) parasitizing Lipaphis erysimi (Kaltenbach) (Hemiptera: Aphididae) in Brassica juncea variety Pusa bold. Munis Entomology and Zoology, 5:692-696.

Balabanidou V, Grigoraki L \& Vontas J (2018) Insect cuticle: a critical determinant of insecticide resistance. Current Opinion in Insect Science, 27:68-74.

Belinato TA \& Martins AJ (2016) Insecticide resistance and fitness Cost. Insecticides resistance. Available at: http://dx.doi.org/ 10.5772/61826. Accessed on: February 1 1', 2018.

Blackman RL \& Eastop VF (2007) Taxonomic issues. In: van Emden HF \& Harrington R (Eds.) Aphids as Crop Pests. Wallingford, CABI. p. 01-30.

Blackman RL \& Eastop VP (2000) Aphids on the world's crops: an identification and information guide, $2^{\mathrm{a}}$ ed. Chichester, John Wiley \& Sons. 466p.

Breda MO, Oliveira JV, Marques EJ, Ferreira RG \& Santana MF (2011) Inseticidas botânicos aplicados sobre Aphis gossypii e seu predador Cycloneda sanguinea em algodão-colorido. Pesquisa Agropecuária Brasileira, 46:1424-1431.

Cayetano L, Rothacher L, Simon JC \& Vorburger C (2014) Cheaper is not always worse: strongly protective isolates of a defensive symbiont are less costly to the aphid host. Proceedings of The Royal Society B, 282:01-10.

Chen DQ, Montllor CB \& Purcell AH (2000) Fitness effects of two facultative endosymbiotic bacteria on the pea aphid, Acyrthosiphon pisum, and the blue alfalfa aphid, $A$. kondoi. Entomologia Experimentalis et Applicata, 95:315-323. 
Chen X \& Stelinski LL (2017) Resistance management for Asian citrus psyllid, Diaphorina citri Kuwayama, in Florida. Insects, 8:01-20.

Dang K, Doggett SL, Veera Singham G \& Lee CY (2017) Insecticide resistance and resistance mechanisms in bed bugs, Cimex spp. (Hemiptera: Cimicidae). Parasites \& Vectors, 10:01-32.

Eggers-Schumacher HA (1983) A comparison of the reproductive performance of insecticide-resistance and susceptible clones of Myzus persicae. Entomologia Experimentalis et Applicata, 34:301-307.

Faria ABC (2009) Revisão sobre alguns grupos de inseticidas utilizados no manejo integrado de pragas florestais. Ambiência, $5: 345-358$.

Ferreira SE, Sampaio MV, Oliveira RS \& Vasconcelos HL (2018) Parasitism rate of Myzus persicae (Sulzer) by Diaeretiella rapae (McIntosh) in the presence of an alternative, resistant host. Revista Brasileira de Entomologia, 62:13-18.

French-Constant RH, Daborn PJ \& Le Goff G (2004) The genetics and genomics of insecticide resistance. Trends in Genetics, 20:163-170.

Foster SP, Denholm I, Poppy GM, Thompson R \& Powell W (2010) Fitness trade-off in peach-potato aphids (Myzus persicae) between insecticide resistance and vulnerability to parasitoid attack at several spatial scales. Bulletin of Entomological Research, 101:659-666.

Gaber AS, Abd-Ella AA, Abou-Elhagag GH \& Abdel-Rahman YA (2015) Field efficiency and selectivity effects of selected insecticides on cotton aphid, Aphis gossypii Glover (Homoptera: Aphididea) and its predators. Journal of Phytopathology and Pest Management, 2:22-35.

Guidolin AS, Cataldi TR, Labate CA, Francis F \& Cônsoli FL (2018) Spiroplasma affects host aphid proteomics feeding on two nutritional resources. Scientific Reports, 8:2466.

Hemingway J (2000) The molecular basis of two contrasting metabolic mechanisms of insecticide resistance. Insect Biochemistry and Molecular Biology, 30:1009-1015.

Hollingsworth RG, Tabashnik BE, Ullman DE, Johnson MW\& Messing RH (1997) Relationship between susceptibility to insecticides and fecundity across populations of cotton aphid (Homoptera: Aphididae). Journal of Economic Entomology, 90:55-58.

Konno RH \& Omoto C (2006) Custo adaptativo associado à resistência de Aphis gossypii Glover (Hemiptera: Aphididae) ao inseticida carbosulfam. Neotropical Entomology, 35:246-250.

Mathenge EM, Gimnig JE, Kolczak M, Ombok M, Irungu LW\& Hawley WA (2001) Effect of permethrin-impregnated nets on exiting behavior, blood feeding success, and time feeding of malaria mosquitoes (Diptera: Culicidae) in western Kenya. Journal of Medical Entomology, 38:531-536.

Mbogo CN, Baya NM, Ofulla AV, Githure JI \& Snow RW (1996) The impact of permethrin-impregnated bed nets on malaria vector of the Kenyan coast. Medical and Veterinary Entomology, 10:251-259.

Miao J, Reisig DD, Li G \& Wu Y (2016) Sublethal effects of insecticide exposure on Megacopta cribraria (Fabricius) nymphs: key biological traits and acetylcholinesterase activity. Journal of Insect Science, 16:01-06.

Nauen R, Ebbinghaus-Kintscher U \& Schmuck R (2001) Toxicity and nicotinic acetylcholine receptor interaction of imidacloprid and its metabolites in Apis mellifera (Hymenoptera: Apidae). Pest Management Science, 57:577-586.
Oliveira RS, Sampaio MV, Ferreira SE, Ribeiro LCM \& TannúsNeto J (2013) Low parasitismo by Diaeretiella rapae (Hym.: Braconidae) of Lipaphis pseudobrassicae (Hemip.: Aphididae): pre- or post-ovipositional host resistance? Biocontrol Science and Technology, 23:79-91.

Oliver KM, Russell JA, Moran NA \& Hunter MS (2003) Facultative bacterial symbionts in aphids confer resistance to parasitic wasps. Proceedings of the National Academy of Sciences, 100:1803-1807.

Paramasivam M \& Selvi C (2017) Laboratory bioassay methods to assess the insecticide toxicity against insect pest - A review. Journal of Entomology and Zoology Studies, 5:1441-1445.

Parra JRP \& Coelho Jr (2019). Applied biological control in Brazil: from laboratory assays to field application. Journal of Insect Science, 19:01-06.

Peña-Martinez R (1992) Identificación de afidos de importância agricola. In: Urias MC, Rodríguez MR \& Alejandre AT (Eds.) Afidos como vectores de vírus en México. Montecillo, Centro de Fitopatologia. p.1-135.

Ritz C \& Streibig JC (2005) Bioassay analysis using R. Journal of Statistical Software, 12:05.

Sampaio MV, Korndörfer AP, Pujade-Villar J, Hubaide JEA, Ferreira SE, Arantes SO, Bortoletto DM, Guimarães CM, SánchezEspigares JÁ \& Caballero-López B (2017) Brassica aphid (Hemiptera: Aphididae) populations are conditioned by climatic variables and parasitism level: a study case of Triângulo Mineiro, Brazil. Bulletin of Entomological Research, 107:410-418.

Silva LD, Omoto C, Bleicher E \& Dourado PM (2009) Monitoramento da suscetibilidade a inseticidas em populações de Bemisia tabaci (Gennadius) (Hemiptera: Aleyrodidae) no Brasil. Neotropical Entomology, 38:116-125.

Schmuck R, Nauen R \& Ebbinghaus-Kintscher U (2003) Effects of imidacloprid and common plant metabolites of imidacloprid in the honeybee: toxicological and biochemical considerations. Bulletin of Insectology, 56:27-34.

Skaljac M, Kirfel P, Grotmann J \& Vilcinskas A (2018) Fitness costs of infection with Serratia symbiotica are associated with greater susceptibility to insecticides in the pea aphid Acyrthosiphon pisum. Pest Management Science, 74:1829-1836.

Stark JD \& Rangus T (1994) Lethal and sublethal effects of the neem insecticide, Margosan-O, on pea aphid. Pest Management Science, 41:155-160.

Starý P, Sampaio MV \& Bueno VHP (2007) Aphid Parasitoids (Hymenoptera, Braconidae, Aphidiinae) and their associations related to biological control in Brazil. Revista Brasileira de Entomologia, 51:107-118.

Stone BS, Shufran RA \& Wilde GE (2000) Life history study of multiple clones of insecticide resistance and susceptible greenbug Schizaphis graminum (Homoptera:Aphididae). Journal of Economic Entomology, 93:971-974.

Szendrei Z, Grafius E, Byrne A \& Ziegler A (2011) Resistance to neonicotinoid inseticides in field populations of the Colorado potato beetle (Coleoptera: Chrysomelidae). Pest Management Science, 68:941-946.

Storch G, Loeck AE, Borba RS, Magano DA, Moraes CL \& Grützmacher AD (2007) Efeitos de inseticidas aplicados em doses subletais sobre a dieta artificial e em lagartas de Anticarsia gemmatalis (Lepidoptera: Noctuidae). Revista Brasileira de Agrociência, 13:75-179.

Tomizawa M \& Casida JE (2003) Selective toxicity of neonicotinoids attributable to specificity of insect and mammalian nicotinic receptors. Annual Review of Entomology, 48:339-364

Rev. Ceres, Viçosa, v. 67, n.3, p. 231-239, may/jun, 2020 
Tran DH, Le KP, Tran HDT \& Ueno T (2016) Control efficacy of pongam (Pongamia pinnata L.) leaf extract against the turnip aphid Lipaphis pseudobrassicae (Davis) (Hemiptera: Aphididae). Journal of the Faculty of Agriculture, 61:141-145.

Tsuchida T, Koga R, Shibao H, Matsumoto T \& Fukatsu T (2002) Diversity and geographic distribution of secondary endosymbiotic bacteria in natural populations of the pea aphid, Acyrthosiphon pisum. Molecular Ecology, 11:2123-2135.
Vorburger C, Ganesanandamoorthy P \& Kwiatkowski M (2013) Comparing constitutive and induced costs of symbiontconferred resistance to parasitoids in aphids. Ecology and Evolution, 3:706-713. 